\title{
ANÁLISE DA ERODIBILIDADE DE SAPROLITOS DE GNAISSE ${ }^{(1)}$
}

\author{
F. MORAIS ${ }^{(2)}$, L. A. P. BACELLAR ${ }^{(3)} \&$ F. G. SOBREIRA ${ }^{(3)}$
}

\begin{abstract}
RESUMO
As voçorocas são freqüentes em áreas com rochas do embasamento cristalino. A evolução destas feições é sempre fortemente condicionada pelos processos de erosão hídrica subsuperficial, embora os processos superficiais também sejam importantes. Este trabalho objetivou investigar os processos erosivos subsuperficiais atuantes nas voçorocas e compreender que fatores mineralógicos e texturais poderiam influenciar a erodibilidade dos saprolitos. Para tanto, foram realizados ensaios de caracterização e de avaliação da erodi bi lidade em amostras representativas, sendo o principal destes o ensaio de furo de agulha. Os resultados indicam que a erosão por carreamento não ocorre e que os saprolitos apresentam susceptibilidade variável à erosão por piping, mesmo quando derivados de uma mesma unidade litológica, mas superior à do horizonte B latossólico. Dados preliminares indicam que os saprolitos mais susceptíveis à erosão por piping são os de textura siltosa (determinados em ensaios granulométricos sem defloculante e agitação) e pobres em minerais agregadores, como os argilominerais.
\end{abstract}

Termos de indexação: solo, erosão, voçoroca, textura, horizonte B.

\section{SUMMARY: ERODIBILITY ANALYSIS OF GNEISS SAPROLITE}

Gully erosion arevery common in areas with gneiss basement rocks. Their devel opment is strongly influenced by subsuperficial processes, although the surface ones are also important. This study aimed to investigatethesubsuperficial erosion mechanisms of these gullies and to understand how mineralogy and texture could influence the saprolite erodibility. Somebasic trials and erodi bility tests werecarried out in representativesamples, with imphasis to especially the pin-holetest. The results showed that seepage erosion does

(1) Trabalho extraído da Tese de Mestrado do autor principal, financiada pela Fundação de Assistência a Pesquisa do Estado de Minas Gerais - FAPEMIG. Recebido para publicação em janeiro de 2003 e aprovado em outubro de 2004.

(2) Geógrafo, Pós-Graduando do Departamento de Geol ogia, Universidade F ederal de Ouro Preto - UFOP. Bolsista de doutorado da CAPES. Campus Morro do Cruzeiro s/n, CEP 35400-000 Ouro Preto - UFOP. E-mail: morais@degeo.ufop.br

(3) Professor do Departamento de Geologia, UFOP. E-mail: bacellar@degeo.ufop.br; sobreira@degeo.ufop.br 
not occur and that saprolitepresent variabl esuscepti bility to pi ping erosi on, even if they are in the same geol ogic unit. The data confirm that soils with Bw horizon (Oxisols) are less erodiblethan any of thetested saprolites. Prelimi nary data suggest that saprolites with a silty texture (determined without dispersant and agitation) and poor in aggregant materials, such as clay minerals, aremore proneto piping erosion.

Index terms: soil, erosion, gully, texture, B horizon.

\section{NTRODUÇÃO}

Grande parte do nordeste e sudeste do Brasil localiza-seem áreas de rochas graníticas e gnáissicas do embasamento cristalino. Na maioria destas áreas, sobretudo nas mais úmidas, o embasamento está recoberto por espessa capa de regolito, muito susceptível à erosão por voçorocas. Entende-se por voçoroca a forma de erosão em canais condicionada pela ação conjunta das águas superficiais e subsuperficiais (DAEE/IPT, 1990).

Por conta de sua grande área de ocorrência, as voçorocas constituem um dos principais riscos ambientais no Brasil (Bertoni \& Lombardi Neto, 1990). Embora ocorram naturalmente no tempo geológico (Bacellar, 2000), grande parte das voçorocas ativas resulta deatividades antrópicas mal planejadas.

Segundo Resende et al. (1995), nas áreas do embasamento cristalino, os horizontes superficiais, sobretudo o B, são mais resistentes à erosão que 0 horizonte C (saprolito). Assim, as voçorocas tendem a se desenvolver plenamente, quando o saprolito é exposto aos processos de erosão (Parzanese, 1991). Todavia, apesar de quase sempre mais alta que a dos horizontes superficiais, a erodibilidade dos saprolitos (horizonte $\mathrm{C}$ ) de rochas do embasamento pode variar até dentro de um mesmo ti po de rocha, dependendo de sutis variações composicionais e texturais (Bacellar, 2000).

A geração das voçorocas pode ocorrer por processos de erosão superficial ou subsuperficial, mas, quando o lençol freático é atingido pelo aprofundamento do canal, os processos subsuperficiais passam a ser preponderantes, o que torna seu controle muito mais difícil e oneroso.

A erosão hídrica subsuperficial atuante nas voçorocas dá-se por dois mecanismos: o primeiro deles está relacionado com o carreamento das partículas menores do solo por entreas maiores, em decorrência da força do fluxo subsuperficial exfiltrante, o que provoca um desmantelamento da estrutura do solo, formando vazios no seu arcabouço. Esse mecanismo é conheci do por seepage er osi on ou erosão por vazamento (Coel ho Netto, 1998) ou carreamento (Rodrigues, 1984). Este mecanismo pode ocorrer em voçorocas com solos finos com textura bimodal (Rodrigues, 1984). O segundo mecanismo é provocado pelo fluxo hídrico em macroporos, que gera forças cisalhantes nas suas margens. Estas forças cisal hantes podem provocar o destacamento e o transporte das partículas, fazendo com que o macroporo se alargue até o ponto em que ocorre colapso do material do teto. Tal mecanismo, que pode surgir em vários tipos de macroporos (ex.: fissuras, cavidades biológicas e juntas de origem tectônica), é conhecido por pi ping ou tunnel erosion (Coelho Netto, 1998). O mecanismo de piping tem sido freqüentemente descrito em estudos sobre voçorocas.

A diferença de erodibilidade entre o horizonte B, pouco erodível, e os saprolitos de rochas do embasamento é facilmente identificável em campo, bem como em ensaios laboratoriais clássicos, como de estabilidade dos agregados e I nderbitzen, dentre outros (Parzanese, 1991; Bacellar, 2000; Santos, 2001). Em contrapartida, as pequenas diferenças de erodibilidade dos saprolitos nem sempre são identificáveis pelos métodos convencionais. A determinação destas diferenças é importante, pois contrastes sutis de erodibilidade no saprolito modificam significativamente as formas e as taxas deavanço das voçorocas eajudam a explicar porque a concentração destas fei ções é diferente mesmo em áreas geol ogicamente homogêneas (Bacellar, 2000).

Por esse motivo, utilizando vários métodos, pretendeu-se, neste trabalho, compreender os processos subsuperficiais de erosão e determinar quais são as variáveis mineralógicas e texturais que influenciariam a erodibilidade dos saprolitos.

\section{ASPECTOS REGIONAIS}

A área estudada situa-se na região sul do complexo de rochas do embasamento cristalino (Complexo Bação), no interior do Quadrilátero F errífero, entre as cidades de Ouro Preto e Belo Horizonte, no centro-sul do estado de Minas Gerais (Figura 1). Nesta região, afloram rochas gnáissicas finamente bandadas, de composição predominantemente granodiorítica (Door, 1969). O mantodeintemperismo énormal mente muito espesso, al cançando local mente até $50 \mathrm{~m}$ de espessura. O saprolito (horizonte $C$ ), que apresenta espessuras de até $40 \mathrm{~m}$, é composto essencial mente por quartzo, fel dspato (variavelmente alterado para caulinita), illita e muscovita (Parzanese, 1991; Sobreira 2000). 


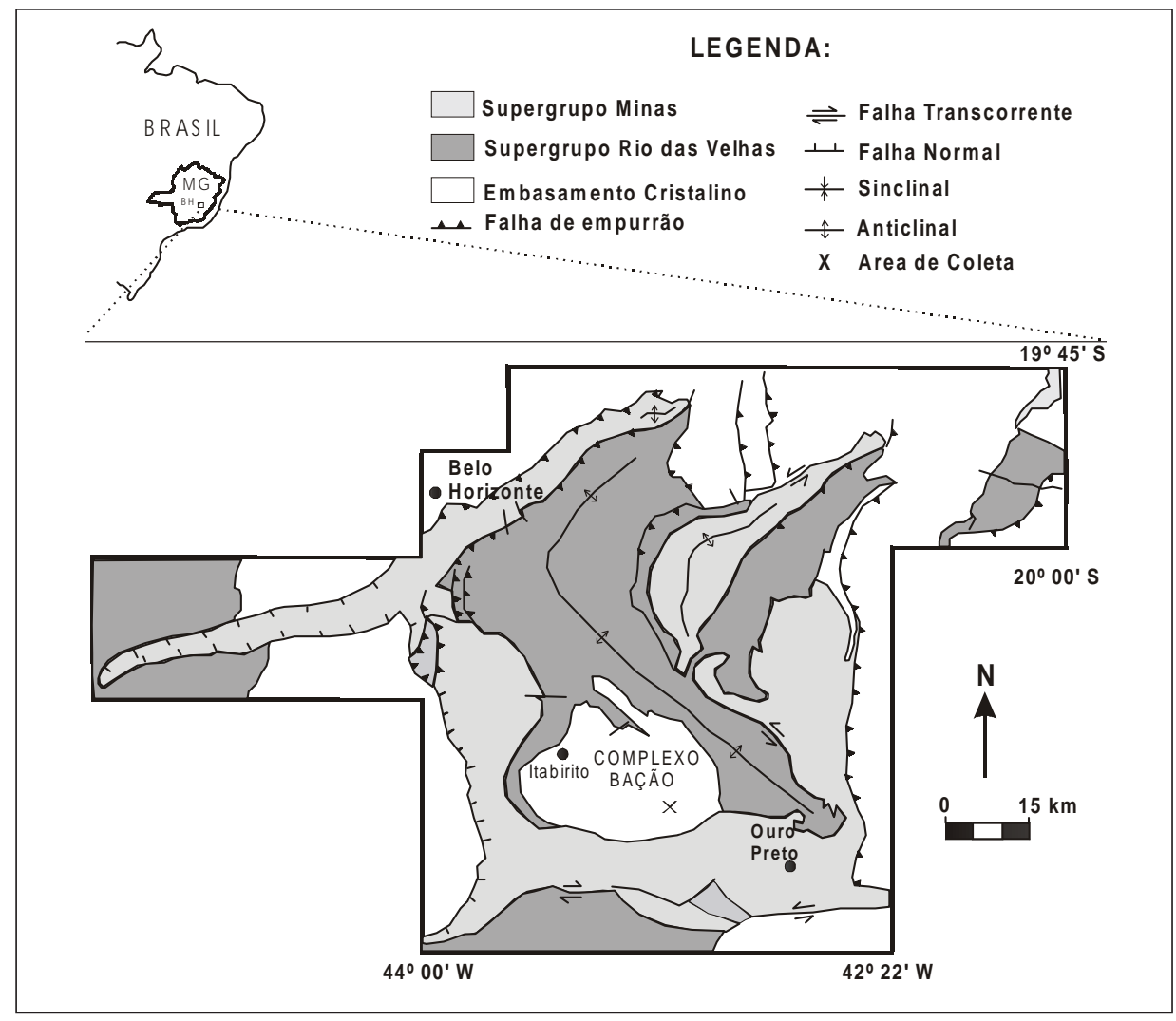

Figura 1. Localização da área de coleta de amostras de solos no Complexo do Bação (MG).

Na região, predominam Argissolos, Latossolos Vermelho-Amarel os e Cambissolos, caracteristicamente argilosos. O horizonte $A$ foi quase totalmente eliminado por atividades antrópicas inadequadas desde o Século XVIII (Parzanese, 1991), enquanto o horizonte $B$, cujas espessuras alcançam até $10 \mathrm{~m}$ (Bacellar, 2000), écomposto predominantemente por caulinita, oxiidróxidos de Fe e Al e quartzo (Parzanese, 1991; Sobreira, 1998).

A erodibilidade dos solos da região tem sido avaliada por métodos de campo, como as parcelas de erosão, e por diversos tipos de ensaios laboratoriais, como estabilidade de agregados, penetração ao cone, desagregação, dispersão, expansãolivree pin-hole(Parzanese, 1991; Sobreira, 1998; Silva, 2000; Bacellar, 2000; Santos, 2001). Estes dados indicam que o horizonte $B$ dos Latossolos, Argissolos e Cambissolos épouco erodível frente aos fluxos hídricos atualmente observados, tanto superficiais como subsuperficiais (Parzanese, 1991; Bacellar, 2000; Silva, 2000; Santos; 2001). Por outro lado, estes mesmos dados confirmam que os saprol itos dos gnaisses da região são normalmente muito erodíveis, tanto nos processos de erosão superficial como subsuperficial, especialmente no processo de piping (Silva, 2000; Morais, 2003). Contudo, a erodibilidade destes saprolitos pode variar significativamente (Bacellar, 2000).

\section{MÉTODOS}

Com base nesses estudos, foram selecionadas áreas representativas dos solos da região, sendo nove amostras de saprolito (horizonte $C$ ) e uma amostra no horizonte $\mathrm{B}$ latossólico, esta para balizar os resultados anteriores. As amostras 1, 2, 3, 4, 6, 7, 8 e 9 foram coletadas no interior de uma mesma voçoroca nas proximi dades da locali idade de Gouveia, enquanto as amostras 5 e 10 em outras duas voçorocas situadas mais a norte. Uma das amostras desaprolito (amostra 1) apresentou, por critérios de campo, maior resistência à erosão, tal como a amostra do horizonte B latossólico (amostra 8).

Estas amostras foram submetidas aos seguintes ensaios de caracterização básica e a outros ensaios indicadores, direta ou indiretamente, de susceptibilidade à erosão:

- Análisegranulométrica (ABNT, NBR 7181/1984).

- Análisegranulométrica sem defloculante(ABNT, NBR 13602/1996), que se diferencia do anterior pela não-utilização de agente dispersor (hexametafosfato de $\mathrm{Na}$, com concentração de $45,7 \mathrm{~g} \mathrm{~L}^{-1}$ ) e deagitador mecânico.

- Limite de liquidez (ABNT, NBR 6459/1984).

- Estabilidade dos agregados (E mbrapa, 1997). 
- Ensaio de furo deagulha (pin-hole) (ABNT, NBR 14114/1998).

- Ensaio de penetração ao cone (Head, 1992).

- Ensaio de expansão livre (Head, 1992).

- Ensaio de desagregação (Silva, 2000).

O ensaio de furo de agulha (pin-hole), conforme o método proposto por Sherard et al. (1976), foi o principal método utilizado para a diferenciação de erodibilidade desses solos. Este é o ensaio mais comumente utilizado para identificar, quantificar a dispersão (coloidal) e classificar os solos argilosos quantoà sua dispersibilidadeem água. No entanto, Camapum et al. (1998) eSilva (2000) demonstraram também sua eficácia para avaliar a erodi bilidade de solos tropicais. Este ensaio consistiu basicamente em escoar água sob diferentes cargas hidráulicas através de um corpo de prova indeformado, cilíndrico, com $2,8 \mathrm{~cm}$ de diâmetro, no qual tenha sido feito um pequeno furo $(\varnothing=1 \mathrm{~mm})$ com uma agulha. As leituras devazão às cargas mai ores (380 e $1.020 \mathrm{~mm}$ ), a observação da col oração do efluente e o diâmetro final do orifício no corpo de prova permitiram definir a susceptibilidade dos solos investigados à erosão por piping. Para avaliar a erosão por carreamento (seepage erosion), foram realizados ensaios com tempo prolongado e sem o furo de agulha nos corpos de prova.

Alcântara (1997) propôs a utilização do ensaio de penetração ao cone para determinar a erodibilidade de solos. Segundo esse autor, a diferença de penetração em amostras saturadas e não saturadas apresentaria boa correlação com a erodibilidade. Este ensaio, normalmente aplicado para determinação do limite de liquidez (Head et al., 1992), consistiu em submeter uma amostra indeformada (de $40 \mathrm{~mm}$ de altura e $73 \mathrm{~mm}$ de diâmetro) ao impacto de um cone (com $300 \mathrm{~g}, 30^{\circ}$ de ângulo de abertura e $35 \mathrm{~mm}$ de altura), deixado cair de uma altura de $10 \mathrm{~mm}$. Mediu-se em cada teste a profundidade de penetração al cançada pela sua ponta em nove pontos diferentes na superfície de cada amostra, tanto na umidade atual (umidade de campo), quanto no estado saturado. A partir dos valores de penetração nessas condições: natural (Pnat) e saturada (Psat), definiu-se a diferença de penetração (DP), conforme a equação:

$$
\mathrm{DP}(\%)=\frac{\text { Psat }- \text { Pnat }}{\text { Pnat }}
$$

Bacellar (2000) demonstrou quea penetração na condição saturada (Psat) mostrou-se mais eficaz que DP para distinguir solos mais erodíveis.

No ensaio de expansão livre, a amostra de solo seco foi passada na peneira de malha de $2 \mathrm{~mm}$ e colocada em uma proveta graduada até atingir o volume de $10 \mathrm{~mL}$. Em seguida, adicionaram-se $50 \mathrm{~mL}$ deágua destilada e, após 30 min de repouso, fez-se a leitura do volume final (V). O índice de expansão livre foi expresso pela seguinte relação:

$$
\text { Expansão Livre }=\frac{\mathrm{v}-10}{10} \times 100 \%
$$

O ensaio de desagregação, freqüentemente utilizado na engenharia para avaliar a erodibilidade, seguiu os procedimentos descritos por Silva (2000), que consistem na modelagem de um corpo de prova cúbico com $6 \mathrm{~cm}$ de aresta e submetêlo a diferentes níveis de submersão, observando-se a desagregação da amostra em cada estádio. A submersão das amostras deu-se em quatro estádios: no primeiro, colocou-se a amostra sobre uma placa porosa submersa em água destilada para saturação por capilaridade por $30 \mathrm{~min}$. Nos dois estádios subseqüentes, el evou-se o nível d'água a 1/3 e 2/3 da amostra durante 15 min. No último estádio, a amostra foi totalmente submersa por $24 \mathrm{~h}$.

Com o intuito de compreender a influência da mineral ogia na erodibilidade, procedeu-se à análise mineralógica sob lupa binocular e por difração de raios X. Os resultados dos ensaios, em conjunto com as características mineralógicas, texturais e estruturais das amostras, foram então analisados, buscando-se o entendimento do comportamento dos saprolitos à erosão subsuperficial .

\section{RESULTADOS}

Os resultados dos ensaios granulométricos com esem defloculante (Figuras 2 e 3 ) mostraram grande variação textural entre os saprolitos (horizonte $C$ ) e entre estes e o horizonte B latossólico (amostra 8). Tais diferenças também foram ser observadas nos demais resultados de caracterização básica (Quadro 1).

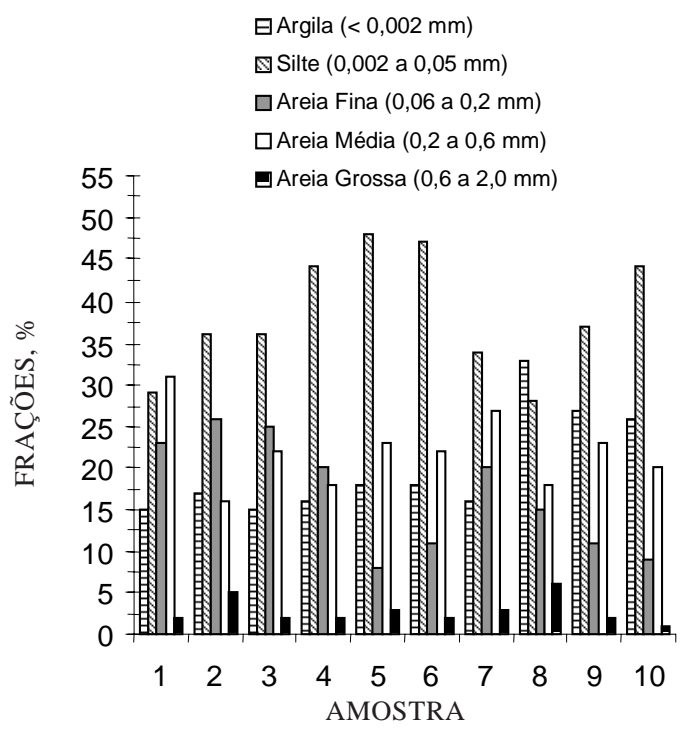

Figura 2. Distribuição granulométrica com uso de defloculante. 
Quadro 1. Caracterização das amostras ${ }^{(1)}$

\begin{tabular}{|c|c|c|c|c|c|c|c|c|}
\hline Amostra & $\begin{array}{l}\text { Limite de } \\
\text { liquidez }\end{array}$ & Expansão & $\begin{array}{c}\text { Massa } \\
\text { específica } \\
\text { natural }\end{array}$ & Umidade $^{(2)}$ & $\begin{array}{c}\text { Massa } \\
\text { específica } \\
\text { dos grãos }\end{array}$ & $\begin{array}{c}\text { Massa } \\
\text { específica } \\
\text { aparente } \\
\text { seca }\end{array}$ & $\begin{array}{c}\text { Índice de } \\
\text { vazios }\end{array}$ & Porosidade \\
\hline & $\mathrm{kg} \mathrm{kg}^{-1}$ & $\%$ & $\mathrm{~g} \mathrm{~cm}^{-3}$ & $\%$ & \multicolumn{2}{|c|}{$\mathrm{g} \mathrm{cm}^{-3}$} & & $m^{3} m^{-3}$ \\
\hline 01 & 0,294 & 18 & 1,77 & 13,7 & 2,34 & 1,56 & 0,50 & 0,330 \\
\hline 02 & 0,358 & 30 & 1,47 & 13,1 & 2,31 & 1,30 & 0,77 & 0,430 \\
\hline 03 & 0,378 & 35 & 1,63 & 18,8 & 2,35 & 1,38 & 0,70 & 0,410 \\
\hline 04 & 0,300 & 35 & 1,74 & 23,7 & 2,65 & 1,41 & 0,87 & 0,460 \\
\hline 05 & 0,390 & 30 & 1,60 & 16,1 & 2,54 & 1,37 & 0,85 & 0,450 \\
\hline 06 & 0,190 & 40 & 1,51 & 7,4 & 2,34 & 1,41 & 0,65 & 0,390 \\
\hline 07 & 0,260 & 39 & 1,81 & 22,0 & 2,62 & 1,48 & 0,77 & 0,430 \\
\hline 08 & 0,470 & 20 & 1,27 & 16,9 & 3,14 & 1,59 & 0,97 & 0,490 \\
\hline 09 & 0,359 & 30 & 1,53 & 9,3 & 2,41 & 1,40 & 0,72 & 0,410 \\
\hline 10 & 0,180 & 40 & 1,55 & 11,8 & 2,34 & 1,39 & 0,68 & 0,400 \\
\hline
\end{tabular}

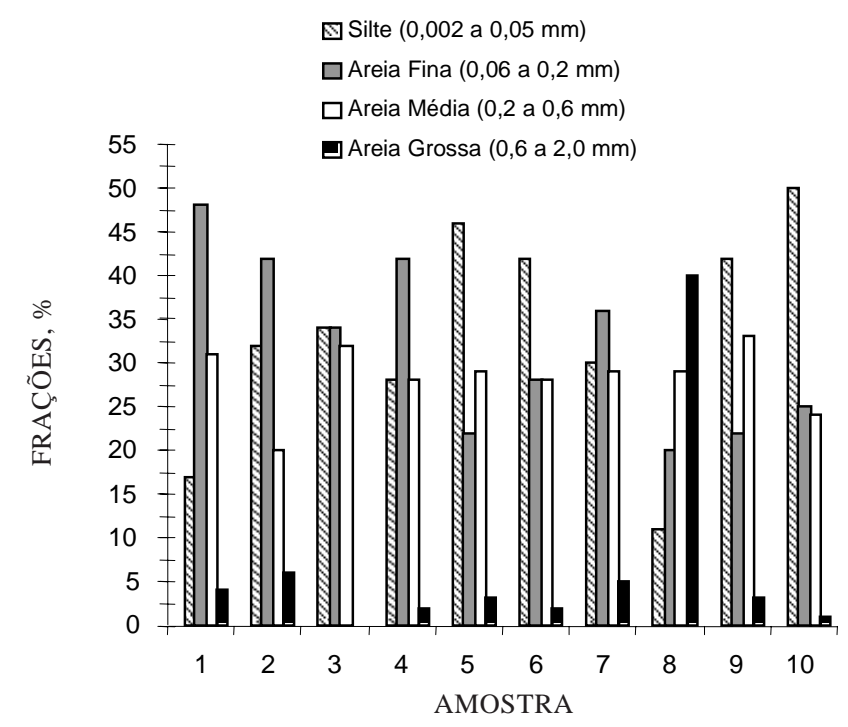

Figura 3. Distribuição granulométrica sem uso de defloculante.

ConformeBacellar (2000), a penetração saturada no ensaio penetrométrico constituiu um bom índice para caracterizar sutis diferenças na erodibilidade de solos de mesma natureza. Assim, foi possível separar as amostras em três grupos quanto à resistência à penetração, sendo as amostras 1 e 8 mais resistentes, as 7, 2, 3, 5 e9, deresistência média, e 6, 10 e 4, de menor resistência (Quadro 2).

Os ensaios de desagregação classificaram as amostras como desagregáveis por abatimento e dispersão, corroborando os dados obtidos por Silva (2000). Estes ensaios permitiram separar as amostras emtrês graus quantoà desagregabilidade(Quadro 3).

Embora tenha ocorrido alguma dispersão dos resultados, decorrentes das heterogeneidades naturais dos solos, os ensai os de pin-hole definiram dois grupos de saprolitos quanto à susceptibilidade
Quadro 2. Resultados dos ensaios de penetração ao cone

\begin{tabular}{crrr}
\hline Amostra & Psat. & Pnat. & DP \\
\hline & \multicolumn{2}{c}{ mm } & \multicolumn{1}{c}{$\%$} \\
\cline { 2 - 3 } 1 & 4,47 & 3,99 & 12,03 \\
2 & 11,09 & 5,13 & 116,18 \\
3 & 11,16 & 5,00 & 123,20 \\
4 & 12,87 & 4,33 & 197,23 \\
5 & 11,59 & 5,88 & 97,11 \\
6 & 17,37 & 5,41 & 221,07 \\
7 & 10,49 & 5,76 & 82,12 \\
8 & 5,51 & 2,28 & 141,67 \\
9 & 10,56 & 4,74 & 122,78 \\
10 & 16,49 & 5,46 & 202,01 \\
& & &
\end{tabular}

Psat.: Penetração saturada; Pnat.: Penetração natural; DP: Diferença de penetração.

Quadro 3. Agrupamento dos solos ensai ados quanto à desagregabilidade

\begin{tabular}{ll}
\hline Grau de desagregabilidade & \multicolumn{1}{c}{ Amostra } \\
\hline Desagregam-se até o 2o estádio & $2,3,4,5,6$ e 10 \\
Desagregam-se no 3o estádio & 1,7 e 9 \\
Não-desagregável & 8 \\
\hline
\end{tabular}

à erosão por pi ping e confirmaram a maior resistência do horizonte B (Figuras 4 e 5 e Quadro 4). Os resultados destes ensaios não comprovaram a influência da estrutura dos saprolitos na erodibilidade, que não variou significativamente em ensaios executados paralelamente ou perpendicularmente ao bandamento das amostras.

Também foram feitos ensaios com o aparel ho de pin-hole, mas sem o furo deagulha (de $1 \mathrm{~mm}$ ), para analisar a susceptibilidade das amostras à erosão 
por carreamento (seepageerosion). Não se observou aumento da vazão nem col oração do efluente, o que demonstra que nenhuma das amostras mostrou-se
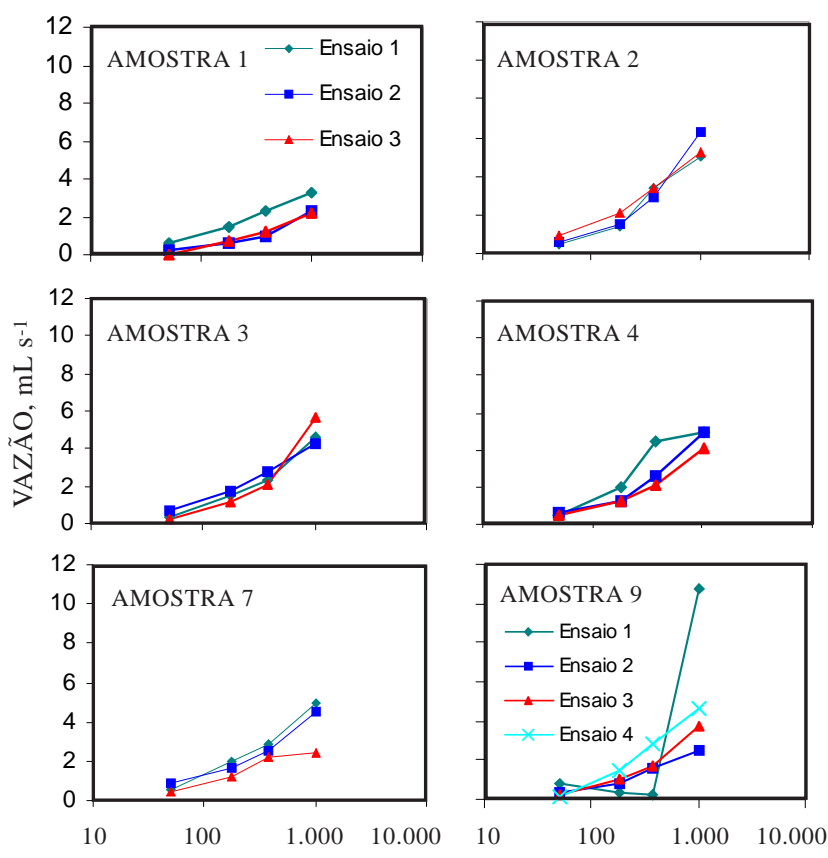

CARGA HIDRÁULICA, mm

Figura 4. Vazão decorrente da carga hidráulica nos ensai os de furo de agulha dos saprolitos menos erodíveis.

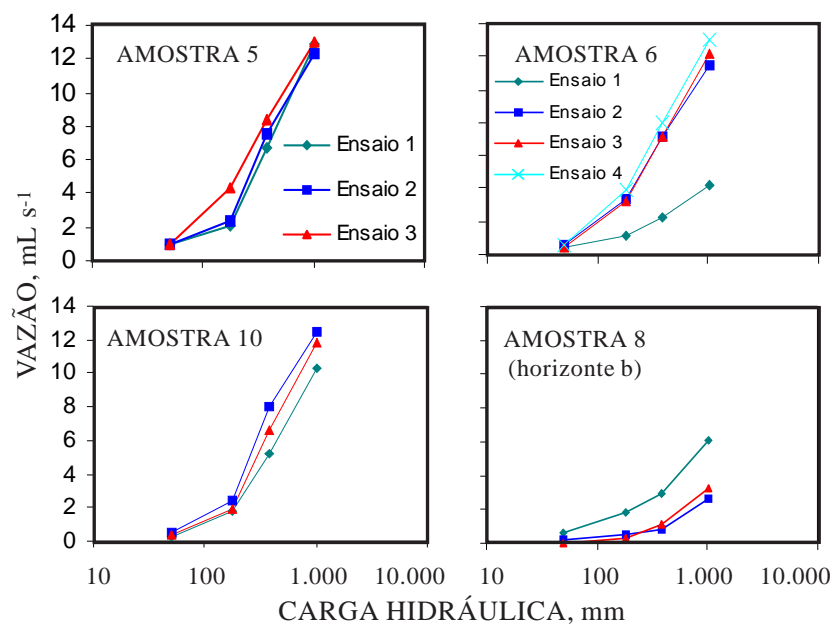

Figura 5. Vazão decorrente da carga hidráulica nos ensaios de furo de agulha dos saprolitos mais erodíveis e do horizonte $B$. susceptível a este mecanismo de erosão, mesmo com aplicação de carga hidráulica máxima (1.020 mm) e com o prol ongamento do tempo de ensaio.

Os resultados de análise mineralógica por lupa binocular mostraram que os solos estudados são basicamente compostos por quartzo, feldspato e fragmentos de rocha. As frações submetidas à análise mineralógica por difração de raios $X$ confirmaram o predomínio do quartzo em todas as amostras, seguido da caulinita e da muscovita. As amostra 2, 1 e 8 foram as mais ricas em caulinita, enquanto, na amostra 2, além desses três minerais, observou-se também a presença de gibbsita.

\section{DISCUSSÃO}

Os resultados das anál ises granulométricas com e sem uso de agente defloculante foram muito diferentes (Figuras 2 e 3 ). Sem defloculante, houve predomínio ora da fração silte, ora da fração areia nos saprolitos, tendo as amostras 10, 6, 5 e 9 apresentado maior percentual de silte. No tocante ao horizonte B latossólico, percebeu-se o predomínio de argila seguida por silte. Notou-se que a grande diferença dos ensaios com defloculante deveu-se à presença da fração argila, que, por encontrar-se agregada, não apareceu nos resultados dos ensaios sem o agente dispersor, sobretudo no horizonte B. Estes dados ea anál ise sob lupa binocular indicaram que os agregados do solo puderam atingir até à dimensão de areia e confirmaram a explícita diferença entre o horizonte B e os saprol itos da área (Parzanese, 1991; Sobreira 1998; Bacellar, 2000; Silva 2000; Santos 2001).

Os ensai os de pin-hole sem furo de agul ha e com tempo prolongado mostraram que estes solos não foram susceptíveis à erosão por carreamento (seepage erosion), mesmo com aplicação de grandes gradientes hidráulicos por $24 \mathrm{~h}$, o que pode ser atribuído ao fato deapresentarem bimodalidadetextural, condição essencial ao desenvol vimento deste mecanismo (Rodrigues, 1984). Em contrapartida, os ensaios de pin-hole convencionais demonstraram que a erosão por pi ping foi possível nos saprolitos, tendo sido os mais erodíveis (amostras 5, 6 e 10) aqueles que apresentaram vazões médias superiores a $10 \mathrm{~mL} \mathrm{~s}^{-1}$ sob carga de $1.020 \mathrm{~mm}$.

Quadro 4. Classificação dos solos quanto à erodibilidade, obtida pelos ensaios de furo de agulha

\begin{tabular}{lcccccccccc}
\hline & \multicolumn{1}{c}{ Amostra } \\
\cline { 2 - 8 } & $\mathbf{1}$ & $\mathbf{2}$ & $\mathbf{3}$ & $\mathbf{4}$ & $\mathbf{5}$ & $\mathbf{6}$ & $\mathbf{7}$ & $\mathbf{8}$ & $\mathbf{9}$ & $\mathbf{1 0}$ \\
\hline Erodibilidade & ND1 & ND2 & ND1-ND2 & ND1-ND2 & D2 & ND3 & ND1-ND2 & ND1 & ND1-ND2 & ND3 \\
\hline D2: Dispersivo; ND1: Não-dispersivo; ND2: Incipientemente Dispersivo; ND3: Levemente Dispersivo. &
\end{tabular}


A susceptibilidadeà erosão por pi ping apresentou boa correlação com a percentagem de silte obtida em ensaios sem defloculante e agitação (M orais, 2003). A única exceção foi a da amostra 9, que, embora siltosa, mostrou baixa taxa de erodibilidade no ensaio de pin-hole (Figura 4). A possível explicação para isto reside no fato de esta amostra apresentar maior teor de partículas decaulinita que as outras amostras ricas em silte (amostras 5, 6 e 10). Assim, a caulinita pode ter agido como agente agregador, dificultando a erosão por piping, comojá sugerira Silva (2000). Em contrapartida, não se observou boa correlação entre os resultados do ensaio de pin-hole e a textura determinada em ensaios granulométricos com defloculante e agitação, o que vem a comprovar que a erodibilidade foi mais bem avaliada em ensaios que reproduzem a textura sob condições próximas às de campo (Bacellar 2000; Silva, 2000; Santos, 2001).

O ensaio de estabilidade de agregados (DMP) permitiu separar o horizonte $B$, menos erodível, dos saprolitos, mais erodíveis, confirmando estudos prévios (Parzanese, 1991). Estes ensaios, porém, não detectaram as sutis diferenças de erodi ibilidade entre os saprolitos, provavelmente por ser a menor peneira utilizada neste ensaio $(0,25 \mathrm{~mm})$ muito maior que a dimensão do silte, que parece ser a fração mais significativa.

Os resultados dos ensai os de penetração ao cone, de expansibilidade e de desagregação não apresentaram correlação satisfatória com os dados de erodibilidade por piping (Morais, 2003), porém indicaram haver uma tendência de os solos mais erodíveis serem mais expansíveis e menos resistentes à penetração saturada, confirmando trabalhos anteriores (Bacellar, 2000). Por fim, as propriedades básicas dos solos (Quadro 1) não exi biram qualquer correlação com a susceptibilidade ao piping.

Portanto, o conjunto de dados permitiram separar três classes de solo quanto à erodibilidade:

Classe 1 (amostras 1 e 8): baixa erodibilidade no ensaio pin-hole; baixa percentagem de silte em ensaios sem defloculante; alta resistência à penetração ao cone; baixa expansibilidade e desagregabilidade nula (amostra 8, horizonte B) a baixa (amostra 1).

Classe 2 (amostras 2, 3, 4, 7 e 9): erodibilidade baixa a média no ensaio pin-hole; percentagem média de silte em ensaios sem defloculante (com exceção da amostra 9); resistência à penetração e expansibilidade médias, e desagregabilidade média (amostra 9) a alta.

Classe 3 (amostras 5, 6 e 10): alta erodibilidade no ensaio pin-hole; alto teor de silte em ensai os sem defloculante; resistência à penetração ao cone baixa (amostras 6e10) a média (amostra 5); expansibilidade alta a média (amostra 5), e alta desagregabilidade.

\section{CONCLUSÕES}

1. Os ensaios de pin-hole demonstraram que a erosão por pi ping mostrou-se possível nos saprol itos derivados de rochas do embasamento da região.

2. Os ensaios pin-hole realizados sem furo de agulha e com tempo prolongado evidenciaram a ausência da erosão por carreamento (seepage erosion) nestes solos.

3. O horizonte B dos solos da região mostrou-se mais resistente à erosão, tanto nos processos superficiais como subsuperficiais.

\section{LITERATURA CITADA}

ASSOCIAÇÃO BRASI LEIRA DE NORMASTÉCNICAS - ABNT. Determinação do limite de liquidez. NBR 6459, fevereiro, 1984.

ASSOCIAÇÃO BRASILEIRA DE NORMASTÉCNICAS - ABNT. Solo - análise granulométrica. NBR 7181, fevereiro, 1984.

ASSOCIAÇÃO BRASILEIRA DE NORMASTÉCNICAS - ABNT. Solo - Avaliação da dispersibilidade de sol os argilosos pelo ensaio sedimentométrico comparativo - Ensaio de dispersão SCS. NBR 13602, maio, 1996.

ASSOCIAÇÃO BRASILEIRA DE NORMASTÉCNICAS - ABNT. Solo - Solos Argilosos dispersivos. Identificação e classificação por meio do ensaio de furo de agulha (Pinhole test). NBR 14114, junho, 1998.

ALCÂNTARA, M.A.T. Aspectos geotécnicos da erodibilidade dos solos. São Carlos, SP, Universidade de São Paulo, 1997. 99p. (Tese de Mestrado)

BACELLAR, L.A.P. Condicionantes geológicos, geomorfológicos e dos mecanismos de voçorocamento na bacia do Rio Maracujá. Ouro Preto, MG Geotécnicos. Rio de J aneiro, Universidade Federal do Rio de J aneiro, COPPE/UFRJ , 2000. 225p. (Tese de Doutorado)

BERTONI, J . \& LOMBARDI NETO, F. Conservação do solo. São Paulo, Í cone, 1990. 355p.

BUENO, B.S. \& VILAR, O.M. Mecânica dos solos. Viçosa, Universidade Federal de Viçosa, 1980. 131p.

CAMAPUM, C.J .; PALOCCI, A. \& SILVA, R.P. Considerações sobre a granulometria de al guns solos do centro-oeste, In: CONGRESSO BRASILEIRO DE MECÂNICA DOS SOLOS E ENGENHARIA GEOTÉCNICA, 11., Brasília, 1998. Anais, Brasília, 1998. v.2. p.1001-1005.

COELHO NETTO, A.L. Hidrologia de encosta na interface com a geomorfologia. In: GUERRA, A.J .T. \& CUNHA, S.B., eds. Geomorfologia - U ma atualização de base e conceitos, 2.ed., Rio de J aneiro, Bertrand, 1998. 472p.

DAEE/IPT. Controle de erosão. Departamento de Águas e Energia Elétrica (DAEE), São Paulo, 1990. 92p.

DOOR, J.N. "Physiographic, and structural development of the Quadrilátero Ferrífero, Minas Gerais". U.S. Geol. Surv. Prof. Paper, V.641-A. 110S, 1969. 
EMPRESA BRASILEIRA DE PESQUISA AGROPECUÁRIA EMBRAPA. Manual de métodos para análise de solo. 2.ed. Rio deJ aneiro, Centro Nacional de Pesquisa de Solos, 1997. 212p.

HEAD, K.H. Manual of soil laboratory testing. 2.ed. London, Pentech Press, 1992. 387p.

MORAIS, F. Estudo dos processos erosivos subsuperficiais na bacia do rio Maracujá-MG. Ouro Preto, Universidade Federal de Ouro Preto, 2003. 98p. (Tese de Mestrado)

PARZANESE, G.A.C. Gênese e desenvolvimento das voçorocas em solos originados de rochas granitóides da região de Cachoeira do Campo, Minas Gerais. Viçosa, Universidade Federal de Viçosa, 1991. 117p. (Tese de Mestrado)

RESENDE, M.; CURI, N.; REZENDE, S.B. \& CORRÊA, G.F. Pedologia: base para distinção de ambientes - Viçosa, NEPUT, 1995. 304p.

RODRIGUES, J .E. Estudo ge otécnico dos fenômenos erosivos acelerados (voçorocas). In: CONGRESSO BRASILEIRO DE GEOLOGIA DE ENGENHARIA E AMBIENTAL, 4., Belo Horizonte, 1984. Anais. Belo Horizonte, Associação Brasileira de Geologia de Engenharia e Ambiental, 1984. p.169182.
SANTOS,C.A. Comportamento hidrológico superficial, subsuperficial ea erodibilidade dos solos da região de Santo Antônio do Leite, distrito de Ouro Preto - MG. Ouro Preto, Universidade Federal de Ouro Preto, 2001. 108p. (Tese de Mestrado)

SHERARD, J .L.; DUNNIGAN, L.P. \& DECKER, R.S. Pinhole test for indentifyng dispersive soils. J. Geotechn. Engin. Divis., 102:69-85, 1976.

SILVA, T.R.M. Caracterização e erodibilidade dos sol os de uma voçoroca na região de Ouro Preto - MG. Rio de J aneiro, Universidade Federal do Rio de J aneiro, PEC/COPPE/ UFRJ , 2000. 106p. (Tese de Mestrado)

SOBREIRA, F.G. Estudo das Erosões de Cachoeira do Campo MG. RelatórioFAPEMIG, UFOP/EM/DEGEO. OuroPreto, 1998. 130p.

SOBREIRA, F.G. Processos erosivos acelerados (voçorocas): O exemplo de Cachoeira do Campo, Ouro Preto, MG. Solos Rochas: R. Latino-Americana Geotec., 254:217-233, 2000.

VARGAS, M. Introdução à mecânica dos solos. São Paulo, McGraw-Hill do Brasil, Universidade de São Paulo, 1978. 509p. 